\title{
Job satisfaction and its modeling among township health center employees: a quantitative study in poor rural China
}

\author{
Jun A Liu*1, Qi Wang² and Zu X Lu
}

\begin{abstract}
Background: Job satisfaction is important to staff management of township health centers (THCs), as it is associated with organizational performance, quality of care and employee retention. The purpose of this study was to measure job satisfaction level of THC employees in poor rural China and to identify relevant features in order to provide policy advice on human resource development of health service institutions in poor regions.

Methods: A self-completion questionnaire was used to assess the job satisfaction and relevant features (response rate: 90.5\%) among 172 employees (i.e., clinic doctors, medico-technical workers and public health workers) of 17 THCs in Anhui and Xinjiang provinces of China. The study covered a time period of two months in 2007.

Results: The mean staff job satisfaction scored 83.3, which was in the category of "somewhat satisfied" on a scale ranging from 0 (extremely dissatisfied) to 100 (extremely satisfied) by employing Likert's transformation formula. Exploratory factor analysis (EFA) revealed eight domains involved in modeling of job satisfaction, among which, the caregivers were more satisfied with job significance (88.2), job competency (87.9) and teamwork (87.7), as compared with work reward (72.9) and working conditions (79.7). Mean job satisfaction in Xinjiang (89.7) was higher than that in Anhui (75.5).

Conclusions: Employees of THCs have moderate job satisfactions in poor areas, which need to be raised further by improving their working conditions and reward.
\end{abstract}

\section{Background}

Job satisfaction is defined as the positive personal perception towards work or work experiences [1]. In fact, job satisfaction has been identified as an important determinant of employee retention, turnover and work performance [2]. In health service sectors, job satisfaction is highly associated with staff's intention to quit, quality and efficiency of services, and patient satisfaction [3]. It has been reported that doctors with higher job satisfaction are more likely to provide more satisfactory services and produce better therapeutic effect than those with the lower one [4]. Therefore, higher job satisfaction tends to result in much higher patient satisfaction and reduce

\footnotetext{
*Correspondence: liujnn2000@yahoo.com.cn

${ }^{1}$ Department of Social Medicine, School of Public Health, Tongji Medical College, Huazhong University of Science and Technology, No.13, Hangkong Road, Wuhan, Hubei Province, PR China

Full list of author information is available at the end of the article
}

medical costs, thereby making a hospital more competitive [5].

Recently, doctor dissatisfaction has become a subject of keen investigation [6]. In 2001, Richard Smith posed a question "Why are doctors so unhappy?" in BMJ, believing that the reasons varied, some of which were deep and complicated [7]. So far, health service institutions in most countries introduced a patient-centered management, which, to some extent, hurt the interest of doctors [8]. Moreover, in 2000, WHO designed a measure of responsiveness to assess the respect of consumers' rights [9]. These moves, unknowingly, erode the rights of doctors, and impair their motivation to better serve patients.

In China, township health centers (THCs) are primary health care organizations, owned by the state or collectives, and provide public health services and primary medical services to above 800 million populations in rural China, which play important roles in the three-tier rural 
health-care network and the "New Rural Corporative Medical System" [10]. However, job satisfaction and retention of THC employees are lower than those of employees working in urban community health centers (CHCs) in China. The Guangdong province is among the richest regions of China, but investigations have shown that job satisfaction of the THC staff in the province was not high, in that caregivers there were not satisfied with their work reward and professional development [11]. Short of long-term governmental investment, some THCs are struggling to survive, especially those in poverty-hit rural areas, which hardly meet the healthcare needs of the local population [12].

To help THCs provide better health services in poor rural China, Chinese Ministry of Health and Hong Kong Kadoorie Foundation elected to launch a Rural Community Health Promotion Project in 2004. One major purpose of the project was to improve overall conditions of THCs, including site construction, provision of basic medical equipment and skill training. In 2005, the project was started in 17 THCs in poor regions of Xinjiang and Anhui. This article was to assess staff job satisfaction of THCs in the poor regions covered by the project and identify critical determinants to job satisfaction, with an attempt to work out strategies to improve the job satisfaction and retention in these institutions.

\section{Methods}

\section{Overview}

The framework of our research is shown in Figure 1. In preparation phase, reports on job satisfaction [13-16] were reviewed and a questionnaire on job satisfaction of THC employees was developed on the basis of both organizational and individual features. The self-completed questionnaire was employed to estimate the job satisfaction of the employees of THCs covered by Kadoorie Project. Quantitative analyses were applied to describe the staff job satisfaction status and identify critical influencing factors and to establish a model of job satisfaction.

In this study, all subjects worked in the fields of clinical, medico-technical, and public health services of 17 THCs, 7 in Anhui and 10 in Xinjiang. Administrators were not included. All the THCs were low-level non-profit medical institutions located in poor rural areas. Seven THCs in Anhui Province were financially independent, and the other 10 institutions in Xinjiang were fully supported by local governments. All the subjects were asked to complete the questionnaire anonymously. Investigators, if necessary, would provide assistance in filling out the questionnaire. Questionnaires took, on average, two hours to fill out in each THC. In the survey, some subjects were too busy with their work to fill out the questionnaires. In the end, a total of 172 employees completed the questionnaires: a response rate of $90.5 \%$.
In order to collect relevant information from respondents, a study design based on epidemiological investigations and face-to-face interviews was conducted by using self-maid questionnaires without any experimental procedures on humans or animals. We promised keeping secret of personal information of all subjects. And all questionnaires were filled anonymously. Therefore this study did not harm the ethics of subjects. All subjects gave their informed consent prior to the study.

\section{Questionnaire}

Various instruments are used to evaluate job satisfaction [17], among which the job description index (JDI) $[16,18]$ and the job satisfaction scale (JSS) [19] are most popular. These instruments, however, are not suitable for assessing job satisfaction of medical or health workers in China. Moreover, no questionnaire is available for the evaluation of job satisfaction of THC workers in rural China. Therefore, on the basis of an extensive literature review, interviews with THC doctors, a careful study of the questionnaire for Chinese urban CHC [13,14], we developed a questionnaire for evaluating job satisfaction of Chinese THC employees.

The job satisfaction instrument for Chinese urban $\mathrm{CHCs}$ included 35 items and was previously used for measuring job satisfaction among GPs [13]. To suit THC staff, the instrument was revised and tailored to the features of THC workers. The job satisfaction questionnaire for THC workers contained only 28 items, covering working conditions, remuneration, cooperation with colleagues, job significance, management and so on (Table 1 ), measured on a 5 -point scale ranging from 1 (extremely dissatisfied) to 5 (extremely satisfied). The instrument also included questions on personal information of THC employees such as age, gender, education background, professional title etc. The items were so arranged that halo effect was avoided.

\section{Data analysis}

\section{Standard 5-point Likert-type scale}

Staff job satisfaction is typically rated on a 5-point Likert scale from 1 (extremely dissatisfied) to 5 (extremely satisfied). And the standard satisfaction scale ranging from 1 to 5 were converted into a 0 -to- 100 scale by utilizing a formula as below.

$$
\operatorname{adjSS}=100 \times \frac{s t d S S-1}{5-1}
$$

Where "adjSS" and "stdSS" are "adjusted satisfaction score" and "standard satisfaction score" respectively.

With the new scoring method, job satisfaction fell into 5 categories: "extremely dissatisfied" (adjSS: 10-29), "dis- 


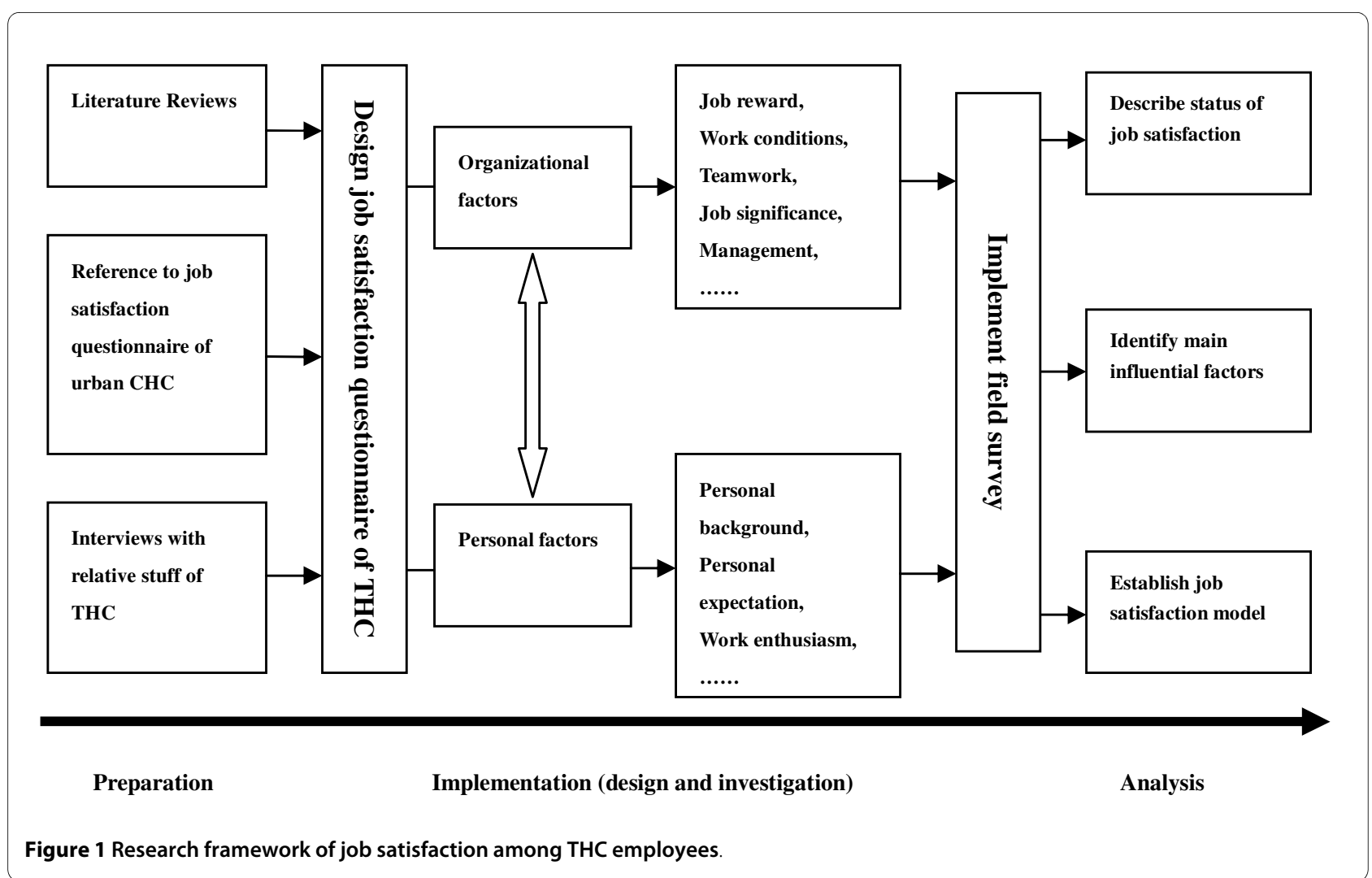

satisfied" (30-49), "generally satisfied or not" (50-59), "satisfied" (70-89), and "extremely satisfied" (90-100).

\section{Exploratory factor analysis (EFA)}

Correlation among the 28 items were found to be weak, and, with a threshold set at 0.8 [20], they were not collinear with each other. Also, regression analysis revealed no multicollinearity. EFA was performed to identify common factors that can cover all the aspects of job satisfaction of the respondents by using principal component analysis and equamax rotation. Eight common factors were extracted, with cumulative initial eigenvalue being $77.88 \%$. Original satisfaction score multiplied by corresponding factor loading equals principal factor scores. The Cronbach's alpha reliability coefficient was 0.851 for entire set of items.

\section{Linear regression analysis}

Stepwise multi-factor linear regression was performed to analyze dependence of staff's total job satisfaction on independent variables as area, gender, age, race, education background, professional title, job type, tenure, pay and the 8 principal factors. In linear regression model, categorical variables were converted to dichotomous dummy variables. Since race and age were respectively related with area and tenure, only one of the two related variables was used at a time in regression modeling to avoid multicollinearity. The $P$ value considered statistically significant was $\mathrm{P}<0.05$. The linear regression model was statistically significant and determination coefficient (R square) was 0.642 , suggesting that the model, to some extent, could interpret the variations of overall job satisfactions of the subjects.

\section{Results}

\section{Demographic Characteristics}

In this study, $172 \mathrm{THC}$ employees, including 66 men (38.4\%) and 106 (61.6\%) women, took part in the investigation, accounting for $80 \%$ of the all health workers (The administrative personnel and employees engaged in logistical services were excluded). Of all the subjects, 77 (44.8\%) were from Anhui and 95 (55.2\%) from Xinjiang. All the Anhui THC workers were Hans, and the Xinjiang subjects were Uighurs. The participants worked in clinical $(\mathrm{N}=75,43.6 \%)$, medico-technical $(\mathrm{N}=52,30.2 \%)$ and nursing $(\mathrm{N}=36,20.9 \%)$ and public health $(\mathrm{N}=9,5.3 \%)$ fields. As to education background, 59 (34.3\%) had a bachelor's degree, $107(62.2 \%)$ received secondary technical education and 6 (3.5\%) did not have any background of medical education. $62.2 \%$ of the respondents were junior professionals. $58.2 \%$ of the subjects received a monthly salary of no more than $1000 \mathrm{RMB}$, but the mean monthly salary (1150 RMB) of Xinjiang THC employees was higher than that (605 RMB) of their Anhui counterparts. 
Table 1: Variables involved in each principal factor and their factor loadings

\begin{tabular}{|c|c|c|}
\hline Common factors & Variables & Loadings \\
\hline Factor 1 & Overall work condition & 0.755 \\
\hline \multirow[t]{4}{*}{ Work conditions and atmosphere (5 items) } & Space of office & 0.693 \\
\hline & Leadership improves work climate & 0.637 \\
\hline & Development improves work condition & 0.627 \\
\hline & Staff adscription from improvement of work condition & 0.512 \\
\hline Factor 2 & Income from salary & 0.786 \\
\hline \multirow[t]{3}{*}{ Job reward (4 items) } & Distribution of rewards & 0.769 \\
\hline & Welfare and treatment & 0.758 \\
\hline & Possibilities of promotion & 0.444 \\
\hline Factor 3 & Suggestions being adopted & 0.693 \\
\hline \multirow[t]{4}{*}{ Work achievements (5 items) } & Abilities fully to play & 0.565 \\
\hline & Busy at work & 0.546 \\
\hline & Achievement from work & 0.555 \\
\hline & Cohesion from work & 0.529 \\
\hline Factor 4 & Competency of knowledge & 0.857 \\
\hline \multirow[t]{2}{*}{ Job competency ( 3 items) } & Competency of skills & 0.793 \\
\hline & Competency being recognized by coworkers & 0.590 \\
\hline Factor 5 & Character of job being self-recognized & 0.704 \\
\hline \multirow[t]{3}{*}{ Job significance (4 items) } & Character of job being recognized by leaders & 0.702 \\
\hline & Character of job being recognized by coworkers & 0.700 \\
\hline & Performance of job being recognized by leaders & 0.502 \\
\hline Factor 6 & Cooperation with coworkers & 0.747 \\
\hline \multirow[t]{2}{*}{ Team work ( 3 items) } & Communication with coworkers & 0.685 \\
\hline & Relationship between coworkers & 0.579 \\
\hline Factor 7 & Management is helpful for development of organization & 0.887 \\
\hline Management (2 items) & Ability of management needs being improved further & 0.869 \\
\hline Factor 8 & $\begin{array}{l}\text { Concern for development of organization } \\
\text { Positive feeling for their work }\end{array}$ & $\begin{array}{l}0.802 \\
0.567\end{array}$ \\
\hline Work enthusiasm ( 2 items) & & \\
\hline
\end{tabular}

Note: Principal components with equamax rotation.

\section{Common factors of job satisfaction}

During EFA, each item in the domains had large factor loadings, ranging from 0.444 to $0.887(\geqq 0.44)$. On the basis of our empirical judgment, the 28 items were categorized into 8 domains (Table 1): The first factor relating to work conditions and atmosphere included 5 items; the second factor concerning job reward involved 4 items; the third factor regarding personal achievements had 5 items; the fourth one about job competency consisted of 3 items; the fifth one relating to job significance contained 4 items; the sixth one about team work included 3 items; the seventh factor about management had 2 items; and the eighth factor concerning work enthusiasm contained 2 items. 


\section{Job satisfaction scores}

The scores of job satisfaction of all the subjects are listed in Table 2. Arithmetic mean of job satisfaction score of all the medical staff was 83.3, equivalent to "somewhat satisfied" on Likert's scale. The average job satisfaction score of the Xinjiang THC staff was 89.7 while that of their Anhui counterparts was 75.5, suggesting job satisfaction was higher in Xinjiang THC workers than in Anhui subjects. Scores reflecting job significance, job competency and team work were highest, with their arithmetic means being $88.2,89.7$ and 87.7 respectively. Work conditions and atmosphere and job reward were lowest, with corresponding average score being 79.7 and 72.2.

\section{Demographic characteristics associated with job satisfaction}

Table 3 shows that age, gender, race, professional title, service time and salary had significant influence on job satisfaction $(\mathrm{P}<0.01)$, while job type and educational level did not $(\mathrm{P}>0.05)$. The average score of job satisfaction in workers 40-49 years old were lower than that of the others $(\mathrm{P}<0.01)$; the score of males was lower than that of females $(\mathrm{P}<0.01)$; the score of Hans was lower than that Uighurs $(\mathrm{P}<0.01)$; the score of the medical workers without professional titles and with a doctor or above professional titles was lower than those with the other titles $(\mathrm{P}<0.01)$; the score of employees working for 16 -30 years was lower than the others $(\mathrm{P}<0.05)$; the score of subjects with monthly salary between 500-800 RMB was lower than the others $(\mathrm{P}<0.01)$.

\section{Linear regression model}

Table 4 presents 10 independent variables in the final multi-factor linear regression model, including race, educational background and all the 8 principal factors contributing to job satisfaction. In the model, standardized partial regression coefficients of work conditions, reward and cooperation with colleagues were greater than the coefficients of the others. In addition, educational background was found to be significantly associated with job satisfaction $(\mathrm{P}<0.05)$. Employees with a bachelor's degree were less satisfied with their work than employees with no medical education (serving as the control) when the other variables were controlled. And job satisfaction of Uighur employees (from THCs in Xinjiang), with other variables controlled, was $16.7 \%$ higher than that of Han workers (from THCs in Anhui).

\section{Discussion}

Staff job satisfaction in THCs has important implications for sustainable development of basic healthcare in China, but so far health decision-makers failed to pay enough attention to job satisfaction of grassroots medical workers. Moreover, they have little knowledge about factors that are associated with job satisfaction and dissatisfaction [21]. Past experience showed that the THCs can not survive and thrive without a team of dedicated workers equipped with adequate medical skills [11]. As primary health service providers, THCs need favorable work environment and conditions to operate efficiently and to meet rational demands of their employees.

According to previous reports, job satisfaction is associated with a wide array of factors, including organizational factors such as job reward and work conditions and personal factors like sense of work achievements and work enthusiasm [22-24]. In our study, exploratory factor analysis was conducted and 8 common factors were identified, which covered virtually all job satisfaction-related factors, such as work conditions, job reward, work achievements, work competency, work significance, team work, management, and work enthusiasm. And compared with JDI that contains the 5 domains (work, compensation, promotion opportunities, superiors, and co-

Table 2: Job satisfaction scores in $\mathbf{8}$ job satisfaction domains

\begin{tabular}{|c|c|c|c|}
\hline Variables & $\begin{array}{c}\text { Anhui's THCs } \\
\text { mean score (SD) }\end{array}$ & $\begin{array}{l}\text { Xinjiang's THCs } \\
\text { mean score(SD) }\end{array}$ & Total score \\
\hline Job significance & $82.6(12.0)$ & $92.7(10.0)$ & 88.2 \\
\hline Job competency & $83.8(11.2)$ & $91.3(9.4)$ & 87.9 \\
\hline Team work & $81.9(10.6)$ & $92.4(9.3)$ & 87.7 \\
\hline Work enthusiasm & $78.2(15.6)$ & $90.9(9.6)$ & 85.2 \\
\hline Management & $78.3(14.0)$ & $88.8(11.9)$ & 84.1 \\
\hline Work achievements & $73.4(16.3)$ & $87.5(11.7)$ & 81.2 \\
\hline $\begin{array}{l}\text { Work conditions and } \\
\text { atmosphere }\end{array}$ & $71.6(19.1)$ & $86.3(15.9)$ & 79.7 \\
\hline Job reward & $54.2(21.1)$ & $86.8(12.9)$ & 72.2 \\
\hline Total score & 75.5 & 89.7 & 83.3 \\
\hline
\end{tabular}


Table 3: Demographic characteristics associated with staff job satisfaction

\begin{tabular}{|c|c|c|c|c|}
\hline Variables & Groups & $\mathbf{N}$ & Score & $\mathbf{P}$ \\
\hline \multirow[t]{4}{*}{ Age (years old) } & No more than 30 & 66 & 87.3 & $0.002^{* *}$ \\
\hline & $30-39$ & 77 & 81.1 & \\
\hline & $40-49$ & 22 & 78.0 & \\
\hline & $50-60$ & 7 & 86.5 & \\
\hline \multirow[t]{2}{*}{ Gender } & Male & 66 & 79.5 & $0.001^{* *}$ \\
\hline & Female & 106 & 85.7 & \\
\hline \multirow[t]{2}{*}{ Race } & Han & 84 & 76.3 & $<0.001 * *$ \\
\hline & Uighur & 88 & 90.0 & \\
\hline \multirow[t]{4}{*}{ Job type } & Clinic & 75 & 82.0 & 0.101 \\
\hline & Nursing & 52 & 86.5 & \\
\hline & Medico-technique & 36 & 82.7 & \\
\hline & Other else & 9 & 78.4 & \\
\hline \multirow[t]{5}{*}{ Professional title } & Doctor in charge or above & 18 & 79.7 & $0.001^{* *}$ \\
\hline & Doctor & 55 & 79.9 & \\
\hline & Assistant doctor & 52 & 84.5 & \\
\hline & Primary health worker & 37 & 89.7 & \\
\hline & No technical title & 10 & 78.6 & \\
\hline \multirow[t]{4}{*}{ Educational background } & Bachelor degree holders & 6 & 88.7 & 0.090 \\
\hline & Junior college graduates & 53 & 79.6 & \\
\hline & Technical secondary school graduates & 107 & 84.9 & \\
\hline & No medical educational background & 6 & 80.8 & \\
\hline \multirow[t]{6}{*}{ Tenure (years) } & $1-5$ & 31 & 89.2 & $0.011^{*}$ \\
\hline & $6-10$ & 56 & 82.6 & \\
\hline & $11-15$ & 39 & 82.6 & \\
\hline & $16-20$ & 26 & 78.9 & \\
\hline & $21-30$ & 13 & 79.9 & \\
\hline & Over 30 & 7 & 89.5 & \\
\hline \multirow[t]{5}{*}{ Salary (RMB per month) } & No more than 500 & 24 & 85.5 & $<0.001^{* *}$ \\
\hline & $500-799$ & 40 & 76.9 & \\
\hline & $800-999$ & 36 & 81.6 & \\
\hline & $1000-1499$ & 49 & 86.1 & \\
\hline & Over 1499 & 23 & 89.0 & \\
\hline
\end{tabular}

${ }^{*} p<0.05 *{ }^{* *} p<0.01$

workers) [25], our self-designed questionnaire was more comprehensive, and suitable for the Chinese medical employees working at poverty-stricken rural area in evaluating job satisfactions. Our results showed that the job satisfaction model in this study had greater explanatory power $\left(R^{2}=0.642\right)$ and was more reliable (the Cronbach's alpha reliability coefficient was 0.851 ). Our study provides a good starting point for further development of standard scale for measuring job satisfaction of workers engaged in THC services in poor rural China.
In the study, we found that the mean score of job satisfaction of workers covered by Kadoorie project was 83.3, which was at "somewhat satisfied" level on Likert's scale. We also found that most staff considered their job to be of importance and got along well with their fellow workers. What they felt most dissatisfied with were work reward (i.e. welfare, pay, and promotion opportunity), working conditions, and sense of work achievements [22]. In the field survey, we noticed that some caregivers complained that salary was too low, considering their experience and skill 
Table 4: Results of multi-factor linear regression analysis

\begin{tabular}{|c|c|c|c|c|c|}
\hline Relative factors & $\begin{array}{c}\text { Partial regression } \\
\text { coefficients }\end{array}$ & Standard error & $\begin{array}{l}\text { Standardized partial } \\
\text { regression coefficients }\end{array}$ & $\mathbf{T}$ & $\mathbf{P}$ \\
\hline Constant & 4.692 & & & & \\
\hline Work conditions and atmosphere & 0.261 & 0.028 & 0.463 & 9.408 & $<0.001$ \\
\hline Job reward & 0.228 & 0.033 & 0.406 & 6.922 & $<0.001$ \\
\hline Work achievements & 0.131 & 0.027 & 0.232 & 4.773 & $<0.001$ \\
\hline Job competency & 0.054 & 0.027 & 0.096 & 2.024 & 0.045 \\
\hline Job significance & 0.151 & 0.028 & 0.269 & 5.410 & $<0.001$ \\
\hline Team work & 0.173 & 0.030 & 0.308 & 5.755 & $<0.001$ \\
\hline Management & 0.152 & 0.027 & 0.271 & 5.580 & $<0.001$ \\
\hline Work enthusiasm & 0.163 & 0.028 & 0.290 & 5.907 & $<0.001$ \\
\hline Race(Uighur) & 0.188 & 0.076 & 0.167 & 2.466 & 0.015 \\
\hline Education (Bachelor's degree) & -0.130 & 0.060 & -0.107 & -2.159 & 0.032 \\
\hline
\end{tabular}

$\mathrm{R}^{2}=0.642, \operatorname{adj} \mathrm{R}^{2}=0.617(\mathrm{~F}=26.060, \mathrm{p}<0.001)$

levels, which substantially hurts their work enthusiasm. Other related studies demonstrated that medical workers were more satisfied with their work and team, while less satisfied with job reward and opportunities of professional promotion $[25,26]$. Compared to urban medical institutions, grassroots heath service units have poor work conditions and fewer promotion opportunities. Therefore, inability to realize personal value has been a major concern of medical workers at THC in poor rural China.

THC employees had higher job satisfaction in Xinjiang than in Anhui. This might be due to relatively higher level of job reward THC that the employees in Xinjiang could receive. Actually, since Xinjiang province was a frontier region located in northwest China, where most residents were Uighurs, the national government invested a lot to support rural health services in the region and THC employees there receive more than a monthly salary of $1000 \mathrm{RMB}$, approximately twice that received by THC employees in Anhui. At present, for health workers in poor rural areas, salary has become a critical factor that influences job satisfaction of THC employees. Herzberg [27] believed that pay, work conditions, job security and relation with colleagues are essential factors that dictate job satisfaction. And failure to meet the demands of employees in these regards will lead to complaints. Moreover, job satisfaction was found to be inversely related with turnover of employees [28], i.e., poor job satisfaction is linked to high turnover [16,29]. If most employees, especially backbone ones, in a THC intend to quit, the result will be disastrous. At present, high turnover among high-quality doctors engaged in THC has been a major threat to the survival of THCs in the rural China [30], which needs to be addressed immediately.
Personal factors, such as age, gender and race also impact on job satisfaction. According to previous reports, females tend to be more satisfied with their job than males [26], and a U-shaped relation was observed between age and job satisfaction [31]. Our results were consistent with these findings. Males, middle-aged and higher professional title holders in our series were least satisfied with their job. However, these caregivers are main force of THCs and care more about their work environment and professional development. Therefore, policy-makers and THC supervisors should address their demands and concerns to bring their talents into full play.

At present, it is necessary to design a well-tailored job satisfaction instrument for Chinese medical staff working in impoverished regions. This study is a preliminary effort to achieve the goal. Compared with the JDI instrument [25], which has 14 items, and the JSS instrument $[6,19]$ that consists of 10 items, our self-designed questionnaire is relatively more complicated and time-consuming, which may pose a problem with busy medical staff. Additionally, because the sample size of our study was comparatively small, studies of large cohorts need to be conducted to further revise and perfect this questionnaire.

The response rate (90.5\%) in our study was higher than that $(81.2 \%)$ reported by Yin et al. [14], that (73\%) by Magne et al. [6] and that (75\%) by Nicholas et al. [25]. This might be because the supervisors of the THCs under Kadoorie Project attached great importance to the investigation. Assessing staff job satisfaction was an important part of the project evaluation, the supervisors asked their employees to fully cooperate with the investigators. And the investigators provided guidance when the subjects 
had any problems with the completion of the questionnaire.

However, there are still some limitations with the research. The project covered only 17 THCs in two provinces; the sample size was comparatively small, which might, to some extent, affect the stability of multi-factorial analysis. Moreover, this investigation was only a cross-sectional study on the results of the project and had no baseline data for comparison. This more or less impairs the power of our study. Care should be exercised in the interpretation and extrapolation of our findings.

\section{Conclusions}

In conclusions, THC employees have moderate level of job satisfaction in poor areas covered by Kadoorie Project. THC employees are more satisfied with the work significance and cooperation with colleagues, while less satisfied with work conditions, reward and promotion opportunities. To enhance staff job satisfaction, THC supervisors should take measures to improve work conditions, raise work reward and pay more attention to the professional development of their employees.

\section{Competing interests}

The authors declare that they have no competing interests.

\section{Authors' contributions}

$J A L$ and $Z X L$ jointly conceived the ideas for the study. JAL was responsible for the data collection in study fields. QW took care of the data analysis and all authors took part in the result interpretation. JAL prepared manuscript. All authors were involved in the revision of the paper and approved the final version.

\section{Acknowledgements}

The study was financially supported by The Hong Kong Kadoorie Foundation and Social Science Foundation of Huazhong University of Science and Technology, Wuhan, China.

\section{Author Details}

1Department of Social Medicine, School of Public Health, Tongij Medical College, Huazhong University of Science and Technology, No.13, Hangkong Road, Wuhan, Hubei Province, PR China and 2Department of Epidemiology and Biostatistics, School of Public Health, Tongji Medical College, Huazhong University of Science and Technology, No.13, Hangkong Road, Wuhan, Hubei Province, PR China

Received: 6 May 2009 Accepted: 10 May 2010

Published: 10 May 2010

\section{References}

1. Howard M: Deconstructing job satisfaction: Separating evaluations beliefs and affective experiences. Hum Resource Manage Review 2002, $12: 174$

2. Sibbald B, Enzer I, Cooper C, Rout U, Sutherland V: GP job satisfaction in 1990 and 1998: lessons for the future? Fam Pract 1987, 17:364-371.

3. Huey M, Shake K, Richand W: Relationship of nurses assessment of organizational culture, job satisfaction and patient satisfaction with nursing care. Int J Nurs Stud 2002, 39:80-84.

4. Katz A: Better outcome means more job satisfaction: pilot project Winnipeg and Halifax to enhance physician-patient communication. Can Fam Physician 1999, 45:218-22.
5. John O: Smart thinking for challenged health systems. Mark Health Serv 2002, 2:24-28

6. Nylenna M, Gulbrandsen P, F\&\#248;rde F, Aasland OG: Unhappy doctors? A longitudinal study of life and job satisfaction among Norwegian doctors 1994-2002. BMC Health Serv Res 2005, 5:44-50.

7. Smith R: Why are doctors so unhappy? BMJ 2001, 322:1073-1074

8. Daghio MM, Ciardullo AV, Cadioli T, Delvecchio C, Menna A, Voci C, Guidetti P, Magrini N, Liberati A: GPs' satisfaction with the doctor-patient encounter: Findings from a community-based survey. Fam Pract 2003, 20:283-288

9. WHO: The World Health Report 2000-health systems: Improving performance. [http://www.who.int/whr/2000/en/index.html].

10. $\mathrm{Yu} \mathrm{N}$, Jiang $H, Y u X$, Le $H$ : Exploration on management of township health centers. Med Soc 2007, 9:27-29. (in Chinese)

11. Guo Y, Chen S: A survey of satisfaction on doctors in the township hospitals in Guangdong province. Chinese Rural Health Serv Admin 2006, 12:20-22. (in Chinese)

12. Fang $L$, Gerald B: Benefit, validity and performance of township health centers: Case study of two township health centers under system transition. World Surv Res 2007, 11:21-27. (in Chinese)

13. Yin W, Fu H, Yan F, Feng X, Wang K: Evaluation on the current state of job satisfaction and stability of community health services staff in three cities. Chinese J Health Stat 2006, 5:421-425. (in Chinese)

14. Yin W, Wang K, Fu H: Research on the scope of job satisfaction and stability of community health workers. Chinese J Hosp Admin 2003 6:351-355. (in Chinese)

15. Boyt TE, Lusch RF, Naylor G: The role of professionalism in determining job satisfaction in professional services. J Serv Res 2001, 3:321-330.

16. Parsons SK, Simmons WP, Penn K, Furlough M: Determinants of satisfaction and turnover among nursing assistants: The results of a statewide survey. J Geronto/ Nurs 2003, 29:51-58.

17. Gillies DA, Foreman M, Pettengill MM: Satisfaction of nurse managers in long-term care. J Geronto/ Nurs 1996, 22:33-40.

18. Smith PC, Hulin CL, Kendall LM, Locke EA: The development of a method of job satisfaction: The Cornell studies. In Studies in Personnel and Industrial Psychology 3rd edition. Edited by: Fleishman EA, Bass AR. Homewood, IL: Dorsey Press; 1974

19. Warr P, Cook J, Wall T: Scales for the measurement of some work attitudes and aspects of psychological well-being. J Occup Psychol 1979, 52:129-48

20. Kennedy P: A guide to econometrics. 3rd edition. Cambridge, MA: MIT Press: 1979.

21. Nicholas GC, John E, Ruth AA: Job satisfaction of nursing home administrators and turnover. Med Care Res Rev 2007, 64:191-211.

22. Rahul N, J Tim N, Katie A: A comparison of career satisfaction amongst dental healthcare professionals across three health care systems: Comparison of data from the United Kingdom, New Zealand and Trinidad \& Tobago. BMC Health Serv Res 2006, 6:32

23. Mika K, Anna V, Jaana P, Hannakaisa L, Marianna V, Marko E, Jussi V: Team climate, intention to leave and turnover among hospital employees: Prospective cohort study. BMC Health Serv Res 2007, 7:170-178.

24. Robert G, Pascale L, Raynald P, Paul AL: Primary care practice à la carte among GPs: using organizational diversity to increase job satisfaction. Fam Pract 2007, 24:138-144.

25. Nicholas GC, Howard D, Jules R: Determinants of staff job satisfaction of caregivers in two nursing homes in Pennsylvania. BMC Health Serv Res 2006, 6:60-71

26. Fiona F, Divine I, Anthony S: What influences the job satisfaction of staff and associate specialist hospital doctors? Health Serv Manage Res 2007, 20:153-161

27. Herzberg Fl, Mausner B, Snyderman B: The motivation to work. 2nd edition. New York: John Wiley; 2007.

28. Pathnlanl DE, Konrad TR, Williams ES, Scheckler WE, Linzer M, Dougla SJ: Physician job satisfaction, dissatisfaction, and turnover. J Fam Pract 2002, 51:593.

29. Bergman R, Eckerling S, Golander H, Sharon R, Tomer A: Staff composition, job perceptions, and work retention of nursing personnel in geriatric institutions. Int J Nurs Stud 1984, 21:279-293. 
30. Zhang J, Wu X, Li A: Current situation analysis and policy advice of health human resources of township health centers in Hubei provinces. Chinese Prim Health Care 2005, 3:3-7. (in Chinese)

31. Kwangho JM, Jae M, Sung DH: Do age, gender, and sector affect job satisfaction? Results from the Korean labor and income panel data. Review Publ Personnel Admin 2007, 27:125-146.

\section{Pre-publication history}

The pre-publication history for this paper can be accessed here: http://www.biomedcentral.com/1472-6963/10/115/prepub

\section{doi: 10.1186/1472-6963-10-115}

Cite this article as: Liu et al., Job satisfaction and its modeling among township health center employees: a quantitative study in poor rural China BMC Health Services Research 2010, 10:115

Submit your next manuscript to BioMed Central and take full advantage of:

- Convenient online submission

- Thorough peer review

- No space constraints or color figure charges

- Immediate publication on acceptance

- Inclusion in PubMed, CAS, Scopus and Google Scholar

- Research which is freely available for redistribution

Submit your manuscript at www.biomedcentral.com/submit
() BioMed Central 